\title{
The time of cholera
}

\author{
David N Fisman MD MPH FRCPC ${ }^{1}$, Kevin Laupland MD MS FRCPC ${ }^{2}$
}

$\mathrm{T}$ he past 18 months have been an extremely difficult period for the country of Haiti - already the poorest country in the western hemisphere (1). In January 2010, Haiti experienced a devastating earthquake, and suffered recent political instability related to a presidential election (2). In addition, cholera cases emerged in October 2010, with the first cases reported in either the Artibonite or Central department of the country (accounts vary); cholera is not known to have caused an epidemic in Haiti previously. Documented, laboratory-confirmed cases were found in the Artibonite by October 21, 2010 (3-5), and the epidemic subsequently spread to all of Haiti's administrative departments. At the time of writing the present note, more than 200,000 cases of cholera had been reported in Haiti; 100,000 individuals had been hospitalized with cholera in a country with a population of just over 10 million. Considering only hospitalized cases, we calculated a percapita attack rate of more than 1000 times higher than the severe acute respiratory syndrome epidemic in Canada (6). Untreated, the disease has a case-fatality rate that may have been in excess of $25 \%$ and has been as high as 15\% (approximately equivalent to that seen with severe acute respiratory syndrome) in some low-resource settings (7-9). Even in the presence of the medical resources available in Haiti, the case-fatality rate has been $2 \%$ in both hospitalized and nonhospitalized cases (10). The reasons for this are unclear: it could be that hospitalization is more reflective of resource availability than disease severity or that more severe cases are hospitalized, but access to resources available in the inpatient setting result in diminished case fatality. Regardless of the reasons for this parity, it is clear that all of these deaths are either directly or indirectly attributable to the inadequate state of water and sewage treatment resources in this country.

\section{CHOLERA AND CONNECTEDNESS}

The precise origins of the Haitian cholera epidemic have not been determined, although news reports and local accounts suggest that the disease may have been introduced into the country as a result of poor sewage management practices at a United Nations military encampment. The strain is an O1 El Tor strain, and is genetically most similar to a strain that has been circulating in South Asia since at least 2002 (11). Importation of cholera is not a new phenomenon: cholera cases are imported into Canada and the United States with some frequency (less than 12 cases per year over the past decade) (12), but the relative wealth of water- and sewage-treatment infrastructure in these countries appears to limit the extent of epidemic spread (13).

Khan et al (14) recently commented on the importance of global 'connectedness' to disease emergence and spread; this appears to be yet another example of connections promoted by the global movement of people and goods facilitating the establishment of an infectious disease in a region where it had not been previously observed (14). Thus, the movement of people to and from Haiti - which is partly a function of the country's unstable political and economic situation - combined with limitations in water and sewage infrastructure, set the stage for the cholera epidemic.

Haiti's cholera epidemic 'internationalized' rapidly, with identification of cases in the Dominican Republic and Florida (USA) within one month of the epidemic's start $(15,16)$; more recently, at least one imported case has been identified in Montreal, Quebec (17).
Travellers visiting the Dominican Republic for a wedding at a resort returned home to Venezuela, Massachusetts (USA) and New York City (USA) with cholera as a result of consumption of lobster, which was presumably contaminated by a cholera-infected food handler (18). To a certain extent, the spread of cholera in the western hemisphere can be predicted based on travel patterns between Haiti and other countries. Figure 1 shows data provided by Dr Kamran Khan of the BioDiaspora Project (www.biodiaspora.com) at St Michael's Hospital in Toronto, Ontario. It can be seen that importation of cholera has thus far occurred in most countries with high volumes of flights to and from Haiti, although in some of these instances (such as cholera case importations in Venezuela, Massachusetts and New York City), cases were actually linked to the Dominican Republic rather than Haiti.

Spatial patterns in the spread of cholera epidemics have long been linked to travel patterns and commerce. In the early 19th century, when the contagiousness of cholera was hotly disputed, the tendency of cholera epidemics to follow shipping routes was identified by supporters of contagionism as a key piece of evidence supporting their school of thought $(19,20)$. Some early 19 th century physicians, such as Daniel Drake, rejected cholera's contagiousness on the grounds that attack rates in attending physicians and nurses were too low, but ingeniously postulated that cholera transmission must be, by some factor, transported by ships. He suggested that the agent of cholera was "poisonous, invisible, aerial insects, of the same or similar habits with the gnat", and drew an explicit analogy to 'intermittent fever' (malaria), going so far as to suggest that window screens, recently introduced by Lancisi in Italy for the prevention of malaria, might prevent cholera (20).

In 1832, cholera made its first documented appearance in North America, imported from Great Britain in ships transporting impoverished Irish immigrants to Quebec City (Quebec). The disease moved rapidly down the St Lawrence River to Montreal, from where it continued along the Great Lakes, with epidemics in Kingston, Ontario, and York (Toronto). At the same time, cholera moved rapidly down Lake Champlain into Vermont (USA) and New York, following the route of the newly completed Erie Canal system to bring cholera to New York City, Philadelphia (USA), and other major hubs on the eastern seaboard (21). In Toronto, a mass grave of cholera victims from the 1832 epidemic, is located under the park adjacent to The Cathedral Church of St James - a short distance from St Michael's Hospital (22).

\section{MANAGEMENT}

The mainstay of cholera management is rehydration and correction of electrolyte imbalances. The cholera toxin is a protein enterotoxin that binds to specific receptors on the intestinal mucosal epithelium, with enhanced production of intracellular cyclic AMP; this in turn results in active pumping of chloride ions into the intestinal lumen, with resultant voluminous watery diarrhea that may rapidly precipitate hypovolemic shock. Passive loss of bicarbonate occurs as well, with resultant metabolic acidosis; loss of potassium ions is associated with neurological and musculoskeletal symptomatology, cramping and cardiac arrhythmias $(23,24)$. Vomiting also frequently occurs and may

${ }^{1}$ Dalla Lana School of Public Health, Toronto, Ontario; ${ }^{2}$ Departments of Medicine, Critical Care Medicine, Pathology and Laboratory Medicine, Centre for Antimicrobial Resistance, University of Calgary, Calgary Laboratory Services, Calgary Health Region, Calgary, Alberta

Correspondence: Dr David N Fisman, Dalla Lana School of Public Health, 155 College Street, Room 678, Toronto, Ontario M5T 3M7.

Telephone 416-978-6866, fax 416-978-7735, e-mail david.fisman@utoronto.ca 


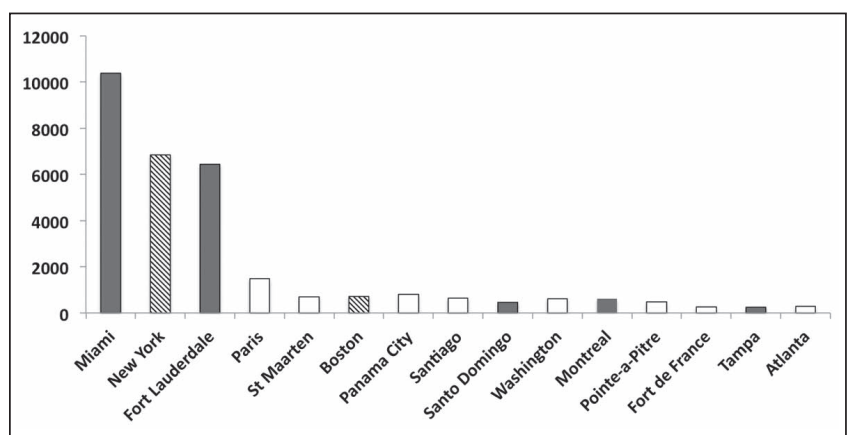

Figure 1) Average monthly airline passenger departures from Port au Prince, Haiti, from October to December, 2009. Grey bars represent airports in jurisdictions that have had cholera case importation from Haiti; hatched bars are airports in jurisdictions that have had imported cholera cases linked to the movement of cholera cases from Haiti to the Dominican Republic; and open bars represent travel volumes for jurisdictions with no reported cholera cases related to the Haitian outbreak as of the time of writing. Data are courtesy of Dr Kamran Khan of the BioDiaspora Project, St Michael's Hospital, Toronto, Ontario

interfere with efforts at resuscitation via oral rehydration, as well as use of antimicrobial therapy $(24,25)$.

Hypovolemic shock may be accompanied by profound hyponatremia, and correction of electrolyte abnormalities must be judicious due to risk of myelinolysis. Indeed, in the context of the current Haitian epidemic, a cluster of individuals identified at a single care centre with fever, gastrointestinal symptoms and flaccid paralysis was initially feared to represent an incipient polio outbreak, but appears rather to have represented an 'outbreak' of myelinolysis due to rapid correction of hyponatremia, rather than flaccid paralysis associated with an alternative infectious agent (26). Current guidelines for the management of cholera are available from the WHO (24).

While the mainstay of therapy for cholera is oral or (in severe cases) intravenous rehydration and management of electrolyte imbalances, antimicrobial agents likely do have a role in cholera management, although their precise indication and role in the management of outbreaks remain controversial, even among expert clinicians with extensive experience with this disease (25). Tetracycline, trimethoprimsulfamethoxazole and erythromycin have all been shown to be superior to placebo (or no antibiotics) in randomized controlled trials evaluating time to cessation of diarrhea in individuals with cholera $(27,28)$. Single-dose ciprofloxacin was subsequently shown to be equivalent to multidose erythromycin regimens, and associated with decreased vomiting (29). More recently, single-dose azithromycin has been shown to be superior to single-dose ciprofloxacin for both clinical and bacteriological cure in both adults and children with cholera $(30,31)$. Because of the reduced volume of diarrhea, reduced duration of illness and reduced infectious bacterial load in stools, it is expected that antimicrobial therapy would not only benefit treated individuals, but might favourably affect disease dynamics in an affected community (25). While current WHO guidelines advocate the use of antimicrobial agents only in individuals with more severe disease, other experts, including those at the International Centre for Diarrhoeal Disease Research, Bangladesh, advocate the use of adjunctive antimicrobials in individuals with less severe disease (5\% to 10\% dehydration) (25). Prophylaxis of contacts is not advocated (25).

An emerging difficulty with antibiotic therapy for cholera is the development of resistance to individual antimicrobials and the emergence of multidrug-resistant strains $(25,32)$. Indeed, it may be that the superiority of azithromycin to ciprofloxacin in a recent clinical trial (30) reflected the diminished utility of ciprofloxacin as a result of resistance. Although the Haitian epidemic strain is sensitive to both azithromycin and tetracyclines, it is resistant to sulfa drugs and nalidixic acid (25), and overly aggressive use of antimicrobial agents may speed the selection of antimicrobial resistant strains, and also favour the emergence of resistance in pathogens that may experience selective pressure incidentally. A variety of mechanisms of antimicrobial resistance have been identified in Vibrio cholerae, and include efflux pumps, chromosomal mutations and mobile genetic elements such as plasmids and SXT elements $(32,33)$.

\section{IMMUNIZATION}

Only one oral cholera vaccine (Dukoral, sanofi-pasteur, France) is currently readily available, and a second vaccine (Shanchol, Shantha Biologics, India) also appears promising. A Cochrane review (34) of the best available evidence suggests that the efficacy of oral vaccines is approximately $50 \%$ for a two-dose vaccine regimen, with the second dose given more than one week and less than six weeks after the first. The duration of effect after initial vaccination is approximately two years, and is three to four years after a booster dose (34). Disease dynamic theory suggests that herd immunity is achieved when a 'critical fraction' (Pc) of the population is vaccinated, and that fraction for a partially effective vaccine relates to the basic reproductive number of the disease $\left(R_{0}\right.$, defined as the number of secondary cases of disease produced by a single case in a totally susceptible population) according to the relation (35):

$$
\text { PC } \times \text { efficacy }>1-\left(1 / R_{0}\right)
$$

Estimates of $\mathrm{R}_{0}$ for cholera are highly variable $(36,37)$, but most are greater than two, suggesting that even with total immunization of the population herd, immunity is unlikely to be achieved. Immunization is, at best, an adjunct to the key preventive strategy of long-term provision of clean drinking water and sewage treatment.

Although WHO guidelines discourage the use of parenteral cholera vaccines, in part, due to low efficacy (in addition to a high risk of adverse effects) $(24)$, Cochrane reviews $(34,38)$ suggest that the efficacy of oral and parenteral vaccines are actually quite similar.

\section{WATER AND INFECTIOUS DISEASE MORTALITY}

An important question confronting any observer of the events that have unfolded in Haiti in recent months is why cholera caused the devastation in Haiti when the technological means to control it so readily were available in most countries in the western hemisphere for more than 100 years (as evidenced by the low impact of cholera importations into the United States, Canada and Venezuela)? The answer relates strongly to economics - prevention of cholera requires long-term investment in infrastructure, which is beyond Haiti's means. The issue goes well beyond Haiti: 'neglected' infectious diseases responsible for a large burden of morbidity and mortality occur disproportionately in countries with limited resources for investment in physical infrastructure, particularly water and sewage treatment infrastructure.

Such infrastructure has been a key component of the reduction in infectious disease mortality that has occurred over the past century in infection-related mortality in wealthier countries (39). Economic historians Joseph Ferrie and Werner Troesken evaluated factors that contributed to the marked increase in life expectancy that occurred at the turn of the 20th century; while pasteurization, immunization and development of antitoxins played important roles, the majority of this transition appears to have been attributable to water filtration and chlorination (40). While global investment in HIV and tuberculosis research has increased markedly in recent years, diarrheal disease research remains underfunded, relative to the burden of disease caused by diarrhea (41). In this sense, cholera and other infectious diarrheal diseases may be the most neglected of the 'neglected infectious diseases'.

\section{REFERENCES}

1. Cox P, Canuto O, Terrier G, Desruell D. Haiti: Enhanced initiative for heavily indebted poor countries - completion point document. $<$ www.imf.org/external/pubs/ft/scr/2009/cr09288.pdf> (Accessed on December 17, 2010). 
2. AOL News. Haiti: A year of suffering. <www.aolnews. com/2011/01/11/haiti-a-year-of-suffering-photos/>. (Accessed on February 17, 2011).

3. Update: Cholera outbreak- Haiti, 2010. MMWR Morb Mortal Wkly Rep 2010;59:1473-9.

4. Cholera outbreak - Haiti, October 2010. MMWR Morb Mortal Wkly Rep 2010;59:1411.

5. Sontag D. In Haiti, capital braces for a cholera outbreak. <www.nytimes.com/2010/10/25/world/americas/25haiti. html?ref=deborahsontag $>$ (Accessed on January 6, 2011).

6. World Health Organization. Summary of probable SARS cases with onset of illness from 1 November 2002 to 31 July 2003. <www.who.int/csr/sars/country/table2004_04_21/en/index.html> (Accessed on February 19, 2011).

7. Siddique AK. Cholera epidemic among Rwandan refugees: Experience of ICDDR,B in Goma, Zaire. Glimpse 1994;16:3-4.

8. Varia M, Wilson S, Sarwal S, et al. Investigation of a nosocomial outbreak of severe acute respiratory syndrome (SARS) in Toronto, Canada. CMAJ 2003;169:285-92.

9. Rogers L. A simple curative treatment of cholera. Br Med J 1910;2:835-9.

10. Ministere de la Sante Publique et de la Population. Documentation of the Haitian cholera epidemic, 2010-11. $<$ http://mspp.gouv.ht/site/index.php?option=com_content\&view $=$ ar ticle\&id $=57 \&$ itemid $=1>($ Accessed on January 10, 2011).

11. Chin CS, Sorenson J, Harris JB, et al. The origin of the Haitian cholera outbreak strain. N Engl J Med 2011;364:33-42.

12. Pan American Health Organization. Number of cholera cases in the Americas (1990-2008). <http://www.paho.org/English/AD/DPC/ CD/cholera-1990-2008.pdf> (Accessed on June 18, 2010).

13. Guerrant RL. Cholera - still teaching hard lessons. N Engl J Med 2006;354:2500-2.

14. Khan K, Arino J, Hu W, et al. Spread of a novel influenza A (H1N1) virus via global airline transportation. N Engl J Med 2009;361:212-4.

15. ProMED-mail. Cholera - Haiti (28): Update and Dominican Republic. <www.promedmail.org> (Accessed on January 5, 2011.)

16. Update on cholera - Haiti, Dominican Republic, and Florida, 2010 MMWR Morb Mortal Wkly Rep 2010;59:1637-41.

17. ProMED-mail. Cholera - Canada: (QC) ex Haiti. <www.promedmail.org> (Accessed on February 16, 2011).

18. ProMED-mail. Cholera - USA (03): (NY) ex Dominican Rep. banquet. <www.promedmail.org> (Accessed on February 16, 2011).

19. Brigham A. Treatise on epidemic cholera including an historical account of its origin and progress to the present period. Hartford: $\mathrm{H}$ and FJ Huntington, 1832.

20. Drake D. A practical treatise on the history, prevention and treatment of epidemic cholera, designed both for the profession and the people. Cincinnati: Corey and Fairbank, 1832.

21. Beck LC. Report on cholera. Transactions of the medical society of the state of New York. Albany: Webster and Skinners, 1832.
22. McGinn D. Back story: Toronto in a time of cholera. $<$ http://network.nationalpost.com/np/blogs/toronto/archive/tags/ Back+story/default.aspx> (Accessed on February 16, 2011).

23. Tauxe R. Cholera. In: Evans AS, Brachman PS, eds. Bacterial Infections of Humans: Epidemiology and Control, 3 edn. New York: Kluwer Academic/Plenum Publishers, 1998:223-42.

24. World Health Organization. Cholera. <http://wwwwhoint/mediacentre/ factsheets/fs107/en/indexhtml $>$ (Accessed on February 2, 2011).

25. Nelson EJ, Nelson DS, Salam MA, Sack DA. Antibiotics for both moderate and severe cholera. N Engl J Med 2011;364:5-7.

26. ProMED-mail. Acute flaccid paralysis - Haiti (03): Osmotic demyelination syndrome, PAHO. <www.promedmail.org >. (Accessed February 16, 2011).

27. Kabir I, Khan WA, Haider R, Mitra AK, Alam AN. Erythromycin and trimethoprim-sulphamethoxazole in the treatment of cholera in children. J Diarrhoeal Dis Res 1996;14:243-7.

28. Islam MR. Single dose tetracycline in cholera. Gut 1987;28:1029-32.

29. Saha D, Khan WA, Karim MM, Chowdhury HR, Salam MA, Bennish ML. Single-dose ciprofloxacin versus 12 -dose erythromycin for childhood cholera: A randomised controlled trial. Lancet 2005;366:1085-93.

30. Saha D, Karim MM, Khan WA, Ahmed S, Salam MA, Bennish ML. Single-dose azithromycin for the treatment of cholera in adults. N Engl J Med 2006;354:2452-62.

31. Kaushik JS, Gupta P, Faridi MM, Das S. Single dose azithromycin versus ciprofloxacin for cholera in children: A randomized controlled trial. Indian Pediatr 2010;47:309-15.

32. Kitaoka M, Miyata ST, Unterweger D, Pukatzki S. Antibiotic resistance mechanisms of Vibrio cholerae. J Med Microbiol 2011.

33. Toma C, Nakasone N, Song T, Iwanaga M. Vibrio cholerae SXT element, Laos. Emerg Infect Dis 2005;11:346-7.

34. Graves P, Deeks J, Demicheli V, Pratt M, Jefferson T. Vaccines for preventing cholera. Cochrane Database Syst Rev 2000;(4):CD000974.

35. Anderson RM, May RM. Infectious Diseases of Humans: Dynamics and Control. New York: Oxford University Press, 1991.

36. Hartley DM, Morris JG Jr, Smith DL. Hyperinfectivity: A critical element in the ability of $V$. cholerae to cause epidemics? PLoS Med 2006;3:e7.

37. Tien JH, Poinar HN, Fisman DN, Earn DJ. Herald waves of cholera in nineteenth century London. J R Soc Interface 2010.

38. Graves PM, Deeks JJ, Demicheli V, Jefferson T. Vaccines for preventing cholera: Killed whole cell or other subunit vaccines (injected). Cochrane Database Syst Rev 2010;(8):CD000974.

39. Armstrong GL, Conn LA, Pinner RW. Trends in infectious disease mortality in the United States during the 20th century. JAMA 1999;281:61-6.

40. Ferrie JP, Troesken W; National Bureau of Economic Research. Death and the city chicago's mortality transition, 1850-1925. <http://papers. nber.org/papers/w11427> (Accessed on Februay 23, 2011).

41. Enserink M. Global health. Some neglected diseases are more neglected than others. Science 2009;323:700. 


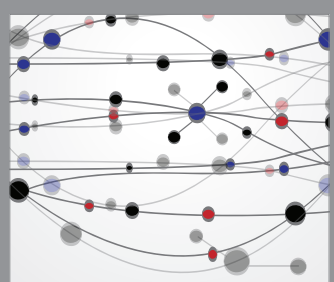

The Scientific World Journal
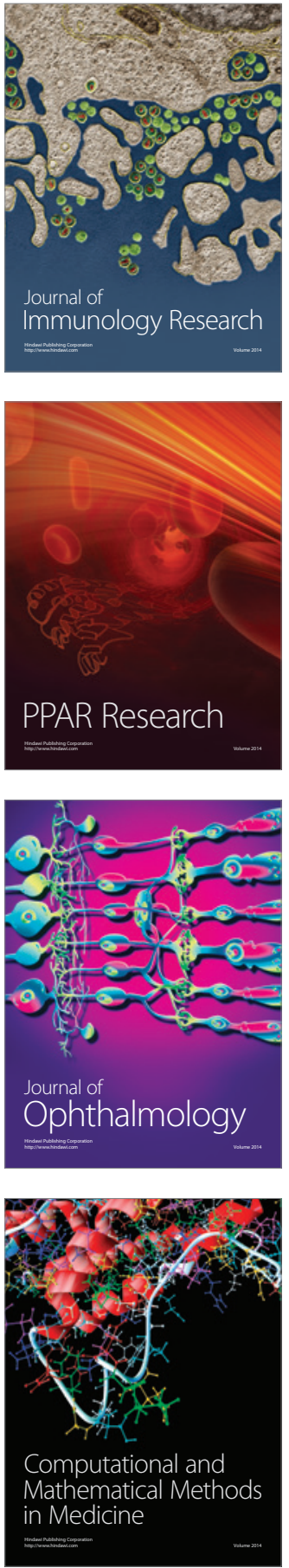

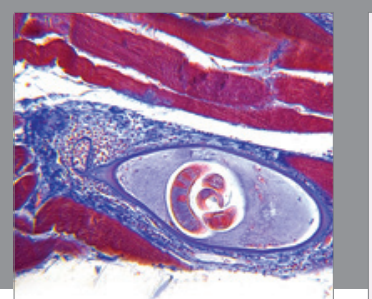

Gastroenterology Research and Practice

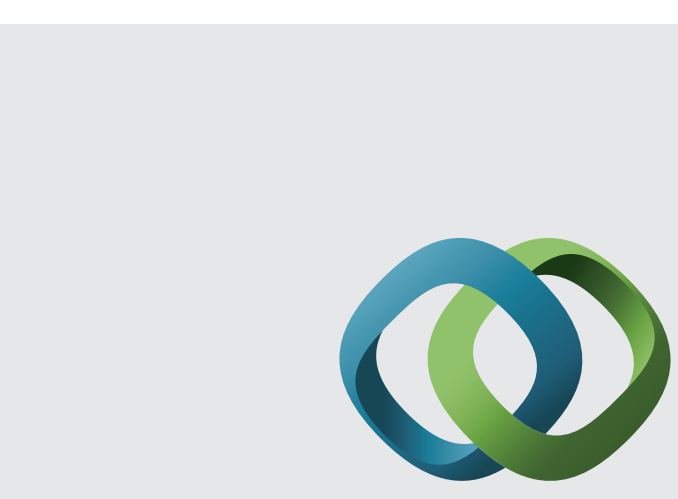

\section{Hindawi}

Submit your manuscripts at

http://www.hindawi.com
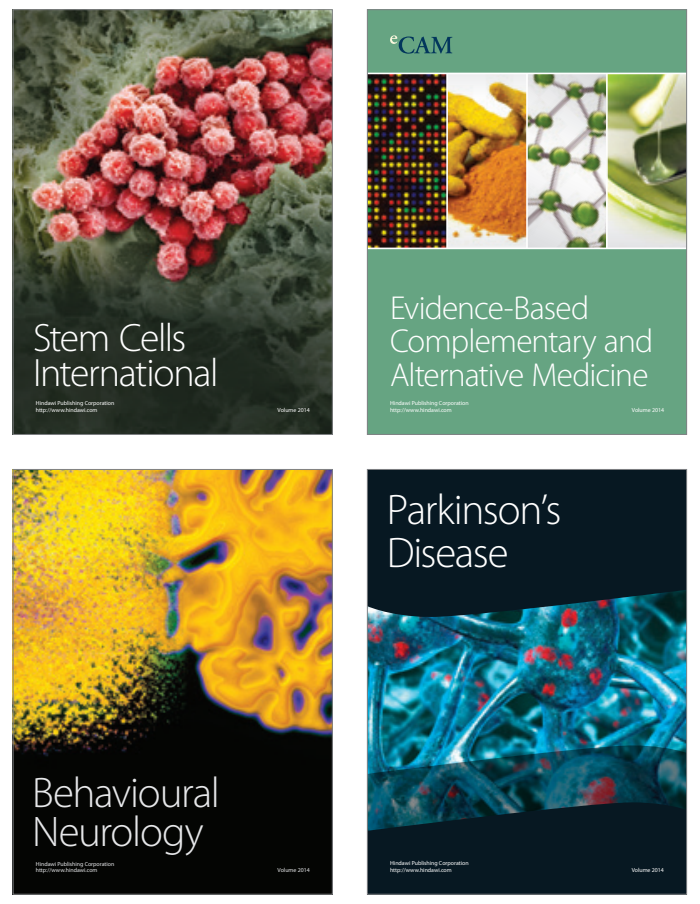
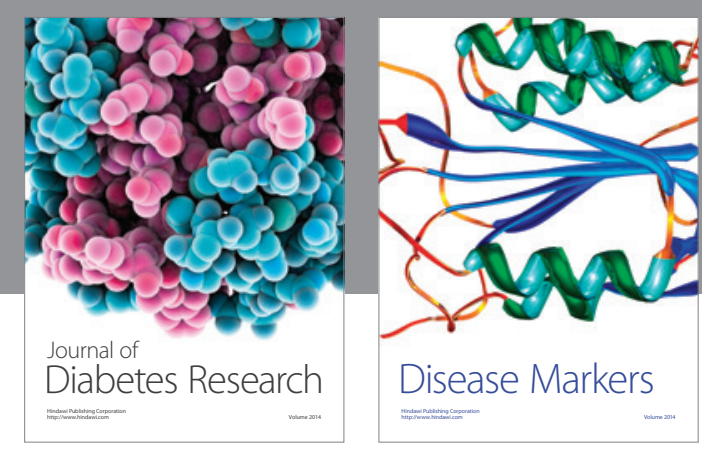

Disease Markers
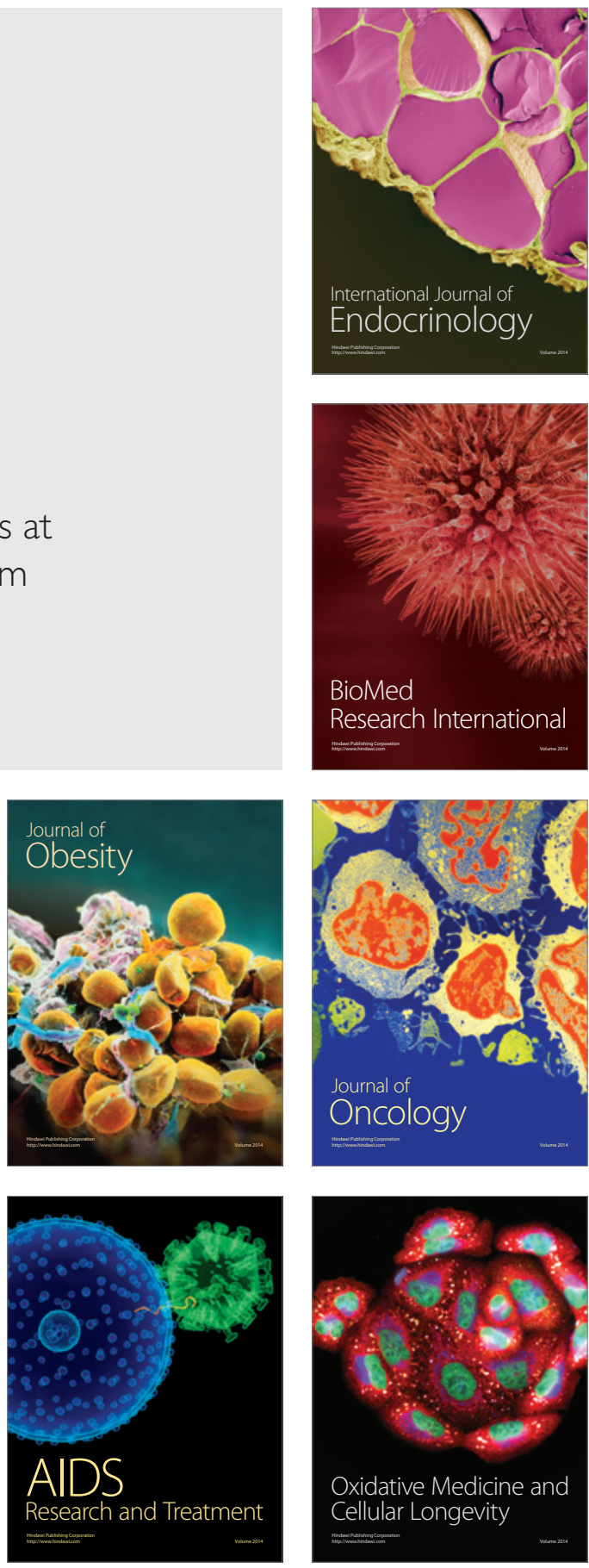